\title{
IMAGEN Y PALABRA EN LA DEVOCIÓN AL SAGRADO CORAZÓN DE JESÚS: UN CUADRO DE P. BATTONIY UN POEMA DE F. ARÉVALO
}

WORD AND IMAGE IN THE WORSHIP OF THE SACRED HEART OF JESUS: A PAINTING BY P. BATTONI AND A POEM BY F. ARÉVALO.

César Chaparro Gómez

Universidad de Extremadura

ABSRACT: In this study I relate the building of the Basilica of Estrela (Lisbon) to the painting by Pompeyo Battoni and the poem by Faustino Arévalo, both dedicated to the Sacred Heart of Jesus, whose worship, suffering a similar fate to that of the suppressed Society of Jesus (1773), went beyond the ecclesiastical sphere and became a source of controversy in the secular milieu of the period.

KEYWORDS: P. Battoni, F. Arevalo, Sacred Heart of Jesus, Jesuits.

RESUMEN: En este trabajo se relacionan la construcción de la basílica de la Estrela (Lisboa) y, especialmente, el cuadro de Pompeyo Battoni y el poema de Faustino Arévalo, dedicados estos últimos al Sagrado Corazón de Jesús, cuyo culto, corriendo una suerte paralela a la de la suprimida Compañía de Jesús (1773), trascendió el ámbito eclesiástico y se convirtió en objeto de controversia en los ambientes profanos de la época.

PALABRAS CLAVES: P. Battoni, F. Arévalo, Sagrado Corazón de Jesús, jesuitas. 
Dada la índole de esta contribución, ajustada a unos parámetros marcados en cuanto a su extensión, dejamos a un lado las necesarias reflexiones introductorias sobre el proceso de construcción social y religiosa que han seguido la imagen y devoción del Sagrado Corazón de Jesús, así como las realizaciones simbólicas, emblemáticas y devocionales que tal construcción ha conllevado en el seno de la Iglesia católica a través del tiempo (Díaz Patiño, 2010). Nos centraremos, pues, en el contenido estricto que avanza el título.

Entre los papeles manuscritos que el jesuita Faustino Arévalo (1747-1824) ${ }^{1}$ depositó en el Colegio Noviciado de Loyola se halla un poema en hexámetros latinos que lleva por título De imagine sacri cordis Jesu ab equite Pompeio Battoni elegantissime depicta, in novo templo Ulissiponensi a Regina fidelissima erecto et sacro Jesu cordi consecrato collocanda. ${ }^{2}$ El cuadro, objeto del tratamiento poético de Arévalo, fue obra del pintor italiano Pompeyo Battoni y ocupa aún hoy el retablo mayor de la llamada Basílica de la Estrela en Lisboa, que originariamente fue un templomonasterio de monjas carmelitas erigido al Corazón de Jesús por la reina María I de Portugal en el año 1779 [fig. 1].

Aparte de su intrínseco valor artístico, la Basílica de la Estrela, el cuadro de Battoni y el poema de Arévalo, poseen otro valor histórico relevante: el de haber sido concebidos y realizados por sus respectivos autores como argumento apologético en la áspera polémica, entablada entre los dos bandos,

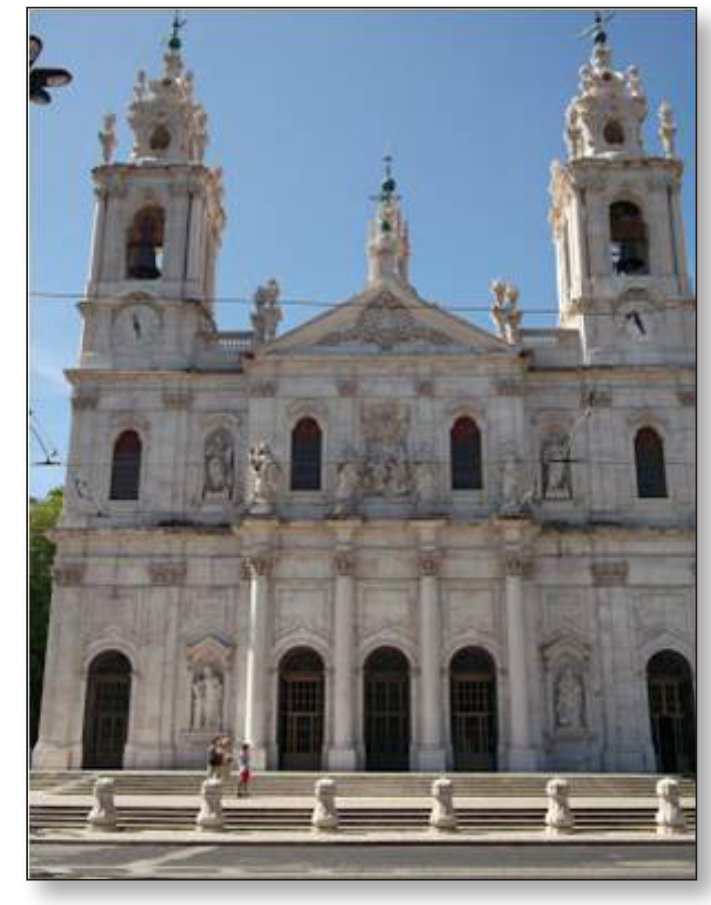

Fig. 1. Basílica de la Estrela. Lisboa.

cordícola y anticordícola, durante la segunda mitad del siglo XVIII, polémica que viene a ser uno de los últimos episodios de la lucha del jansenismo contra la Iglesia católica. Es éste un momento histórico en el que el tema del Corazón de Jesús, saliendo de su propio marco dogmático, ascético y litúrgico, trasciende al terreno cultural y políticoreligioso, convirtiéndose en objeto de controversias enconadas, no solo en los medios eclesiásticos y en las comunidades religiosas, sino también en los ambientes profanos de

1. Faustino Arévalo nació en Campanario (Badajoz) en 1747. Ingresó en la Compañía de Jesús, estudiando Humanidades en Villagarcía de Campos y Filosofía en Medina del Campo. Expulsado de España, cursó Teología en Bolonia, donde se ordenó sacerdote. En 1780 pasó a Roma. Hombre de una vastísima erudición, en 1786 publicó la Hymnodia Hispana; a esta obra siguieron, hasta 1794, las ediciones de las obras de los poetas cristianos Prudencio, Draconcio, Juvencio y Sedulio y, posteriormente, la publicación del Misal Gótico. Por encargo del cardenal Francisco Lorenzana inició la edición, en siete tomos, de las obras de san Isidoro de Sevilla, que no concluyó hasta 1803. En 1800 le fue otorgado el título de Himnógrafo pontificio y, años después (1809), fue nombrado Teólogo de la Penitenciaría. Restablecida la Compañía de Jesús, reingresó en ella y volvió a España a fines de 1815. Fue Rector del Colegio - Noviciado de Loyola. Murió en Madrid, en el antiguo Colegio Imperial, el 13 de Enero de 1824.

2. Su traducción al castellano es: [Poema] a la imagen del Sagrado Corazón de Jesús, elegantemente pintada por el caballero Pompeyo Battoni, que habrá de ser entronizada en el nuevo templo de Lisboa, edificado por la cristianísima Reina y consagrado al Sagrado Corazón de Jesús. 
los cenáculos de los «literatos» y en los salones de las cortes principescas. En realidad, el culto al Sagrado Corazón corría entonces una suerte paralela a la de la suprimida Compañía de Jesús (1773), a la que estaba vinculado íntimamente (Fernández Arrillaga, 1997: 92-95). Unas palabras del P. Manuel Luengo (Colección de Papeles Varios, X, 44) ponen de relieve lo dicho y relacionan los tres elementos que se dan cita en nuestra reflexión (basílica, cuadro y poema):

\begin{abstract}
A la verdad es una cosa que pasma y que nos consuela mucho el ver el vivísimo empeño con que se ha tomado por la presente Reina de Portugal la exaltación de la devoción al Corazón de Jesús, perseguida en todas partes y aun en el estado mismo de la Iglesia, precisamente porque es cosa peculiar en algún modo de la aborrecida Compañía de Jesús[...] Ahora es preciso decir una palabra de la hermosa pintura hecha en Roma y que se ha de colocar en el nuevo templo dedicado al Sagrado Corazón de Jesús en la Corte de Lisboa[...] El célebre Pompeyo Batoni, aunque los dominicos lo negaron en sus gacetas, ha hecho esta gran pintura, y está ya acabada del todo[...] Uno de estos, el P. Faustino Arévalo, de nuestra provincia de Castilla, que vive en Roma, ha compuesto un poemita latino de cuatro o cinco hojas como estas, en el cual describe menudamente y con hermosura y viveza esta gran pintura del Sagrado Corazón hecha por Batoni para ser colocada en la nueva iglesia de Lisboa[...] De todos modos triunfará esta devoción en la Corte de Lisboa y aun en todos los reinos y provincias sujetas a la Corona portuguesa, como se dice en los últimos versos del poemita del P. Arévalo.
\end{abstract}

Tradicionalmente, se ha hablado de dos tipos iconográficos en la representación del Sagrado Corazón de Jesús. Uno de ellos presenta el corazón unido a la persona de Jesucristo, quien ordinariamente de medio cuerpo, muestra su pecho abierto y en él, o sosteniéndolo en su mano, como punto central de la figura, aparece la imagen del corazón con sus clásicos símbolos: llaga, co- rona de espinas, cruz y llamas con resplandores radiantes. El segundo tipo, inspirado en la simbología medieval y en las apariciones y diseños de santa Margarita María de Alacoque, fue vulgarizado por los grabados del P. Gallifet y presenta la imagen del corazón, sola y exenta, sin la apoyatura de la persona física de Jesucristo. Su concepción siempre es idéntica: la sagrada víscera ocupa el centro de la composición, enmarcada por una gloria circular luminosa, con los clásicos símbolos ya mencionados, y rodeada por una pequeña corte de cabezas de serafines en actitud contemplativa y de adoración. La composición tiende a escenificarse con alusiones a la Eucaristía, al purgatorio, etc., y dentro del ciclo que podemos llamar jesuítico, el más abundante tal vez, con alegorizaciones referentes a sus santos y al estado de persecución en que se hallaba la Compañía.

El movimiento jansenista, encabezado en ese momento por los escritos del abogado romano Camilo Blasi, rechazaba por igual estos dos tipos iconográficos. El que representa el corazón solo y exento, por materialista e idolátrico, ya que ofrecía a la adoración un trozo de carne de la Humanidad de Cristo, separado del resto del cuerpo. El del corazón unido a la persona física del Señor, por peligroso e incitativo de la concupiscencia, ya que según Blasi el Señor aparece en figura de joven, de hermoso rostro, rebosante de lozanía, con el pecho desnudo y ofreciendo su corazón cárneo y sonrosado.

\section{EL CUADRO DE POMPEYO BATTONI EN LA BASÍLICA DE LA ESTRELA [FIG. 2]}

Apenas ascendida al trono en 1777, Doña María I de Portugal y como consecuencia de la deposición y procesamiento del Marqués de Pombal (que desterró a los jesuitas de su nación en 1759 y dio varios decretos contra 


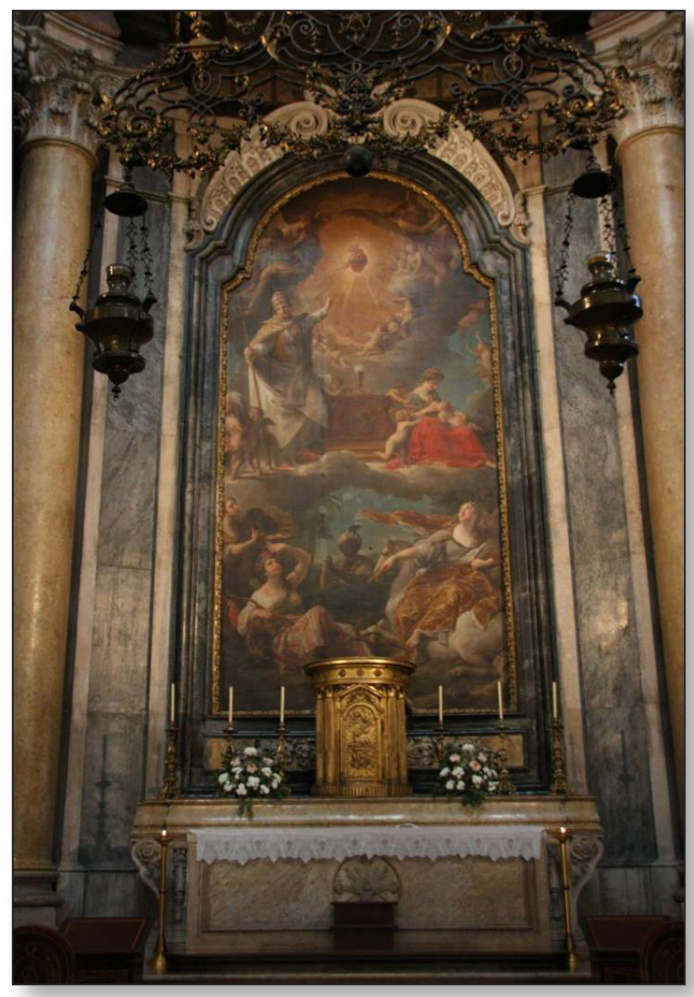

Fig. 2. Pompeyo Battoni. Sagrado Corazón de Jesús. Retablo mayor de la Basílica de la Estrela. Lisboa.

el culto al Sagrado Corazón), no solo sacó de las cárceles a los jesuitas que permanecían en ellas hacía diecisiete años, sino que además se preocupó de restaurar el culto público al Corazón de Jesús en sus dominios y ello lo hizo de dos formas. Una, consiguiendo de Roma la solemne celebración de su fiesta con oficio y misa propios; otra, iniciando las obras de un fastuoso templo votivo al mismo Sagrado Corazón. La insinuación del P. Luengo de que en la erección de este templo influyó el deseo de la reina de dar una satisfacción a la perseguida Compañía, se confirma con las palabras de una carta de Pío VI, respuesta a otra de la reina María. Sin embargo, la razón fundamental de Doña María fue el cumplimiento del voto hecho al Corazón de Jesús de levantar en su honor un templo, si conseguía un hijo varón, como efectivamente lo consiguió, y fue el príncipe que la sucedió con el nombre de Juan VI.

La razón más inmediata de la elección de Battoni para pintar el lienzo titular de la Estrela hay que buscarla en el jesuita italiano P. Javier Calvi, el más activo propulsor de la iconografía del Sagrado Corazón; para ello movilizó a toda una serie de artistas para pintar imágenes de este tema, destinadas a templos de Italia, Francia, Alemania y hasta Canadá y China. El más notable de los pintores utilizados por Calvi, en efecto, fue Pompeyo Battoni, de quien obtuvo entre otros los dos cuadros que instaló en las dos iglesias jesuitas en Roma, la de san Andrés del Quirinal y la del Gesù.

En cuanto al cuadro del retablo mayor del templo votivo de la Estrela, hay que decir en primer lugar que este es uno de los diez lienzos, de grandes dimensiones, que Battoni pintó para toda la basílica. El lienzo titular es una síntesis comprensiva del estilo de Battoni. El neoclasicismo battoniano, inspirado por su minucioso estudio de Rafael, cuya obra fue a estudiar expresamente al Vaticano, aparece en la disposición arquitectónica del lienzo, dividido a imitación del de La Transfiguración del Señor, del de Urbino, en dos grandes zonas de arriba a abajo. Igual que en éste, la parte superior se desarrolla en forma de gloria circular luminosa, de albas y difuminadas coloraciones. Paralelamente, el grupo inferior de las cuatro partes del mundo se adensa en tonalidades y claroscuros más cálidos, igual que la parte baja de La Transfiguración. La sobria mesa central, sobre la que brilla una sencilla custodia con las especies eucarísticas, es una réplica de La Disputa del Sacramento de Rafael. La esbelta figura estante de Pío VI, que enlaza las dos zonas del lienzo, es una obra maestra en la que Battoni mostró sus excepcionales dotes de retratista de papas, emperadores y príncipes. ${ }^{3}$ El alegorismo tan

3. Este retrato no podía menos de halagar a Pío VI, no sólo por su prestancia física, sino como expresión simbólica 
del gusto de Battoni, tanto en los asuntos profanos como en los sagrados, patente en todo el cuadro, se concentra en la personificación de las cuatro partes del mundo. El tema pudiera interpretarse como una concesión tardía al gusto del barroco, pero por su sobrio diseño dibujístico y frialdad naturalista, caen dentro de los cánones neoclásicos. No en vano los contemporáneos llamaron a Battoni el pintor de la natura.

\section{EL POEMA DEL P. FAUSTINO ARÉVALO}

En 1781, año en que está firmado el lienzo de Battoni, Arévalo se hallaba en Roma y llevaba muy adelantada su Himnodia hispánica (1786). En ese tiempo estaba en su punto álgido la polémica cordícola y anticordícola, en la que terciaron un buen número de exjesuitas, principalmente italianos, españoles, portugueses e hispanoamericanos. Arévalo no intervino como otros jesuitas en forma de densos tratados doctrinales y apologéticos (Aguirre, Gadea, Idiáquez, Guevara, Petisco o Marqués); él lo hizo con un poema latino, fruto de la gran preparación humanista que recibió en el colegio de Villagarcía de Campos.

El asunto del poema, compuesto por 253 hexámetros latinos, ${ }^{4}$ se atiene a la descripción sistemática del cuadro de Battoni, partiendo de la imagen del corazón que corona su parte superior, hasta terminar con la personificación de las cuatro partes del mundo, a las que se extendía el imperio portugués. En el poema hay alusiones dogmáticas e históricas fácilmente perceptibles para quien posea unas nociones acerca de la devoción y culto al Corazón de Jesús. En cuanto a su valoración literaria, hay que hacer dos observaciones. La primera se refiere a su valor lingüístico y estilístico, patente en el giro y corrección de las frases y en la estructura de una indiscutible latinitas, de resonancias claramente virgilianas y de una técnica poética irreprochable. ${ }^{5}$ En segundo lugar, las dificultades de vocabulario, inherentes a lo abstracto del tema, así como las propias del alegorismo desarrollado pictóricamente por Battoni, han sido también brillantemente superadas por Arévalo. Aunque la fecha del poema, año 1781, le sitúa en pleno neoclasicismo dieciochesco, del cual sabían mucho Arévalo y sus compañeros españoles del exilio, debe considerársele como un fruto tardío de la poética latina del barroco. En el poema de nuestro jesuita esa tardía filiación barroca está matizada, como no podía menos de suceder, por tópicos ideológicos, rasgos formales y pinceladas de gusto dieciochesco, doblados de neoclasicismo, a tono con la pintura que lo inspira.

En la composición de la pieza poética se pueden distinguir varias partes. La primera de ellas abarca los primeros veinticinco versos, a su vez repartidos en dos apartados, el ámbito literario (vv.1-11) y el artístico pictórico (vv.12-25). En efecto, El poeta empieza contraponiendo su composición con las de la literatura clásica (por ende, pagana), calificadas estas como fútiles «bagatelas, ficciones y ensueños» (vanas nugas

de su actitud decididamente antijansenista en relación con el culto al Corazón de Jesús. En este sentido fue interpretada su visita al estudio de Battoni para contemplar el cuadro antes de ser enviado a Lisboa.

4. El poema ha sido transcrito por Rey (1958), en el artículo citado en la bibliografía, acompañado de una traducción castellana del mismo. Aparte de las variantes textuales (algunas importantes) observadas en el manuscrito original con respecto a la versión impresa por Rey, esta consta de 252 hexámetros, mientras que el manuscrito presenta 253 versos latinos.

5. Los excelentes estudios humanísticos en el Colegio de Villagarcía de Campos, dirigidos por el P. Idiáquez, proporcionaron a Arévalo, como a los jesuitas coetáneos, unos sólidos conocimientos en la composición de obras en latín, preferentemente poéticas (Ruiz Sánchez y Gallego Moya, 1997-1998).

IMAGO, NÚM. 7, 2015, 59-68 
[...] commenta et somnia vatum): el tema nuclear de su poema es el AMOR (carmen amor nostrum), que arde en el corazón divino y cuyas llamas inflaman el corazón humano. A continuación Arévalo fija su mirada (igualmente contrastiva: religio, pietatis amor, cura pudorque [...] frente a impietas, cultusque deum, procaces) en la composición pictórica, haciendo igualmente una comparación con las obras de los genios griegos.

La segunda parte del poema (del verso veintiséis al cincuenta y cuatro) consta, en primer lugar, de un doble panegírico: al autor del cuadro, Pompeyo Battoni, a quien llama "destacado en la piedad y en el arte» (pietate uel arte insignis) y cuyas obras serán contempladas en las edades futuras, cantando así su mérito y fama; y a la reina lusitana María I, que ordenó la construcción del templo en Lisboa y eligió a Battoni para decorar con su pintura el retablo central del mismo. Al final de esta parte, se hace una mención expresa a las monjas carmelitas descalzas ("vírgenes y devotas doncellas»), que contemplarán el cuadro y que cuidarán de su culto a través de los años. El lienzo de Battoni levantará admiración (delicias artis) y, a la vez, inspirará un sentimiento de piedad y de virtud.

A continuación, en una tercera parte, el poeta, haciendo una introducción a la descriptio del lienzo (vv. 55-68), expresa mediante interrogación retórica la imposibilidad de destacar alguna parte del cuadro (Quid primum, quid deinde loquar?). En efecto, Arévalo no sabe por dónde empezar en su descripción del cuadro, en dónde fijarse más. Todo es importante en él: la sangre del corazón, el fuego, la cruz y la corona de espinas; la mesa de la divina cena, la madre que alimenta a sus hijos y el pontífice revestido de pontifical; las heridas que inundan con la luz del corazón las distintas regiones de la tierra. Ojalá, concluye el poeta, pueda conjugar convenientemente poesía y pintura. En un verso se dice: Pictura foret simili quoque nota Poesi, en clara alusión a la fór- mula horaciana ut pictura poesis, que bien conoce y maneja el jesuita Arévalo.

En el verso 68 (hasta el 217) se inicia la descripción del cuadro de Pompeyo Battoni. El poeta la inicia haciendo hincapié en la majestuosidad y grandiosidad del cuadro, en sus exactas proporciones y bella armonía, adecuadas al recinto cultual y al altar, y en la variedad de las figuras existentes en el mismo. En resumen, es una obra proporcionada y simétrica (neoclásica), pero a la vez adornada con figuras llenas de simbología y variedad (barroca): Principio in longum procurrit tela[...] uariis simul apta figuris, ordinibus distincta suis et legibus aequis, amplam quae deceat sedem et superimpleat aram ingentem, annexis hinc atque ornatibus inde.

La descripción empieza por la parte superior del lienzo, en la que se halla la imagen del Sagrado Corazón [fig. 3], adornada entre etéreos nimbos y desplegando bienaventurada luz (coruscat aetherios inter nimbos lucemque beatam Cordis imago Sacri). A la vista queda la enorme herida, de donde mana un río de férvida sangre (ingens vulnus [...] roranti flumine sanguis). La herida producida por la lanza de un soldado, que se ha adentrado en el Corazón, origen de los Sacramentos, simbolizados por la sangre y el agua que manan de él. Este es el significado dado desde antiguo por la Iglesia y los Santos Padres. De igual manera destaca la Cruz, única esperanza de vida, extendiendo sus brazos; y ciñe el corazón una corona de duras espinas (crux[...]brachia, serta spinea Cor cingunt). El corazón encendido desprende rayos luminosos que son fuego, luz y calor e incendia (más que el Vesubio o el Etna) los corazones de los pobres mortales.

En los versos siguientes Arévalo se fija en el coro de jóvenes alados (pennigeri iuvenes) que, venidos del Olimpo, reciben los centelleos del Corazón, al que adoran y velan. Su espíritu es el mismo, pero su aspecto cambia, reflejando motivos diversos: cambian en el tamaño, en la claridad de su contorno (semiocultos, escondidos en la som- 


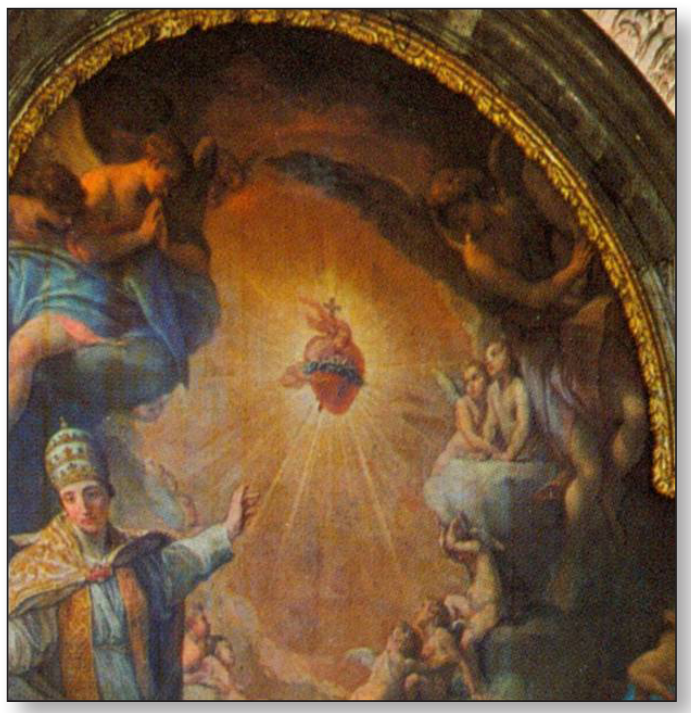

Fig. 3. Sagrado Corazón (Detalle).

bra), en sus posturas, etc. Lo que agrada en el lienzo es su "acorde discordia», la misma adoración descrita en posturas diversas: $i u$ vat discordia concors, diversaque unus descriptus imagine cultus.

No menos arte demuestra el pintor, según Arévalo, al poner más abajo el misterio de la última cena: el áureo cáliz y la hostia de trigo: Dios hecho comida y bebida, como herencia para las generaciones futuras ( $\mathrm{ca}$ lix aureus[...]hostia frugis triticeae[...]potum cibumque praesentis vitae). A la izquierda del altar, asiste al evento una mujer de facciones agradables y bellas, que tiene a un niño en su seno y a quien amamanta, estando a su alrededor otros que imploran el alimento de su leche (praestantissima forma femina [...] sinu puerum tenet[...]nutrit [...] alii lactisque petunt alimenta). Ella simboliza el Corazón vivo, cuyo honor y culto obliga a los hombres a corresponderle igualmente con amor. Es la alegoría de la caridad y del misterio de la Eucaristía.

Las últimas palabras citadas sirven al poeta de engarce con una casi veintena de versos (transición a la descripción del Romano Pontífice), en los que se constata el culto al Sagrado Corazón desde antiguo,

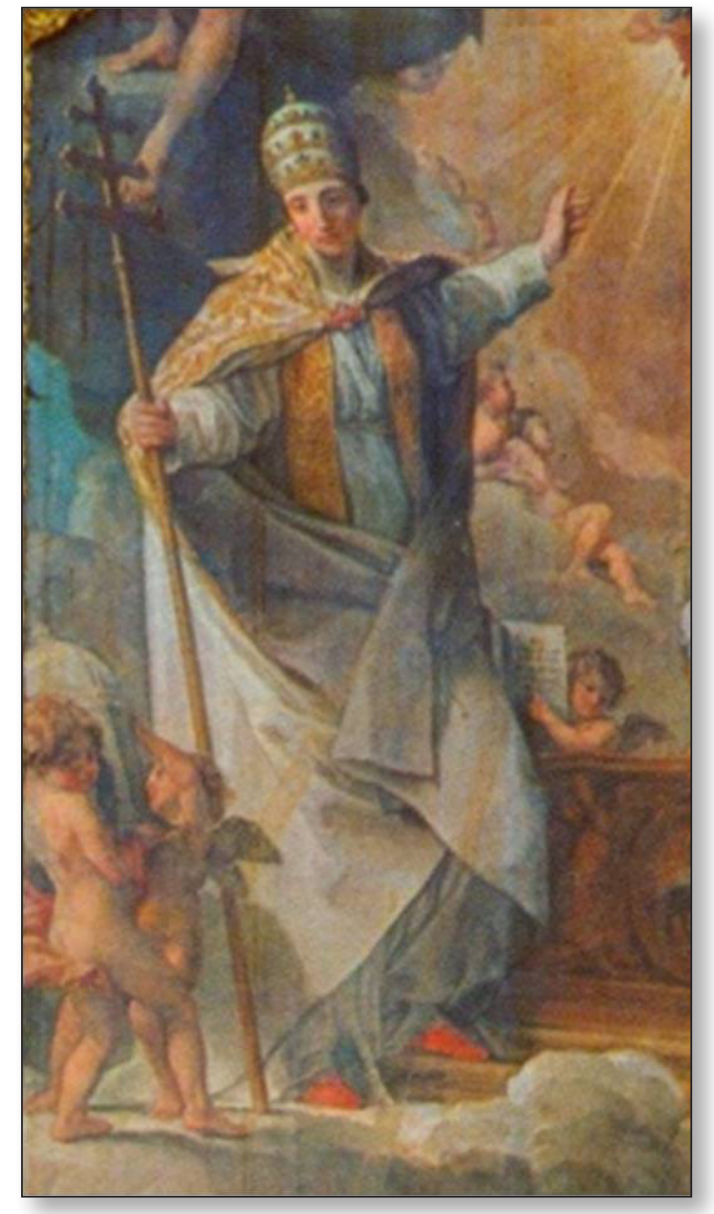

Fig. 4. Sumo Pontífice (Detalle).

pero en un ámbito estrictamente privado, hasta que el Sumo Pontífice le marcó una festividad y un rito propios. Así, desde ese momento, en los templos se celebra públicamente la fiesta del Corazón de Jesús, que arde sin fin, sin que el fuego en su ardor lo consuma

En la parte derecha del cuadro el pintor, en un alarde de intuición y conocimientos, dibujó al Sumo Pontífice [fig. 4] mediante una figura impresionante (uigor et maiestas) y mirando al público (sirve de nexo con el espectador); engalanado asimismo con una triple corona (tiara) de brillantes perlas, resplandece alrededor de sus hombros la púrpura de su capa y la blanca toga roza 
sus plantas rojas (diademate frontem gemmis stellato. Romani splendet amictus circa humeros ostrum, subter toga candida tangit purpureos demissa pedes). El Papa alzando el brazo señala con su mano el Corazón radiante, que proyecta haces de luz, mientras dos ángeles, casi escondidos, sostienen la maqueta de un templo, símbolo de la perennidad de la Iglesia. Del corazón se propagan los rayos ardientes a las cuatro partes del mundo y aunque faltaran propagadores del nuevo culto, este monumento votivo lusitano bastaría para divulgarlo por orillas lejanas, a donde un día llegaron sus naves.

La descripción de Arévalo continúa con la realizada ingeniosamente de las cuatro partes del mundo, en la parte inferior del lienzo, a las que llegan los rayos desprendidos del Sagrado Corazón. En primer lugar aparece Europa montada en caballo blanco (no en el toro legendario), como grave matrona, vestida de azul, con los cabellos recogidos, y ostentando en su diestra el cetro (Albo gaudet equo comptis Europa capillis vesteque caerulea [...] nobile dextra ostentans sceptrum terrae imperiosa minatur) [fig. 5]. A continuación, África de negro semblante, ojos blancos, y turbante que se alza a los vientos; coral rosado pende de su cuello y en su mano lleva el marfil (Africa stat nigro non longe dissita uultu; albescunt oculi, uolitans se uertice ad auras tollit apex, collo rubicunda corallia pendent, candet ebur manibus). La fértil y tórrida América está después, que extiende su mano izquierda para atemperar los rayos y con su derecha acaricia un tigre; lleva en su sien una corona de plumas de muchos colores y luce un vestido listado y con pliegues armoniosos (Dives America cultu torrida siluestri fulgorem exterrita laeua temperat extensa, tigrim manus altera mulcet, diuersis auium ex plumis frons laeta corona uersicolore nitet: uirgatus lucet amictus). Finalmente, casi escondida, aparece Asia con bellos perfiles; perlas de oriente en su sien y en su cuello, sahumerios de incienso y un camello al pie de grotesca cerviz y joroba (Asia [...]

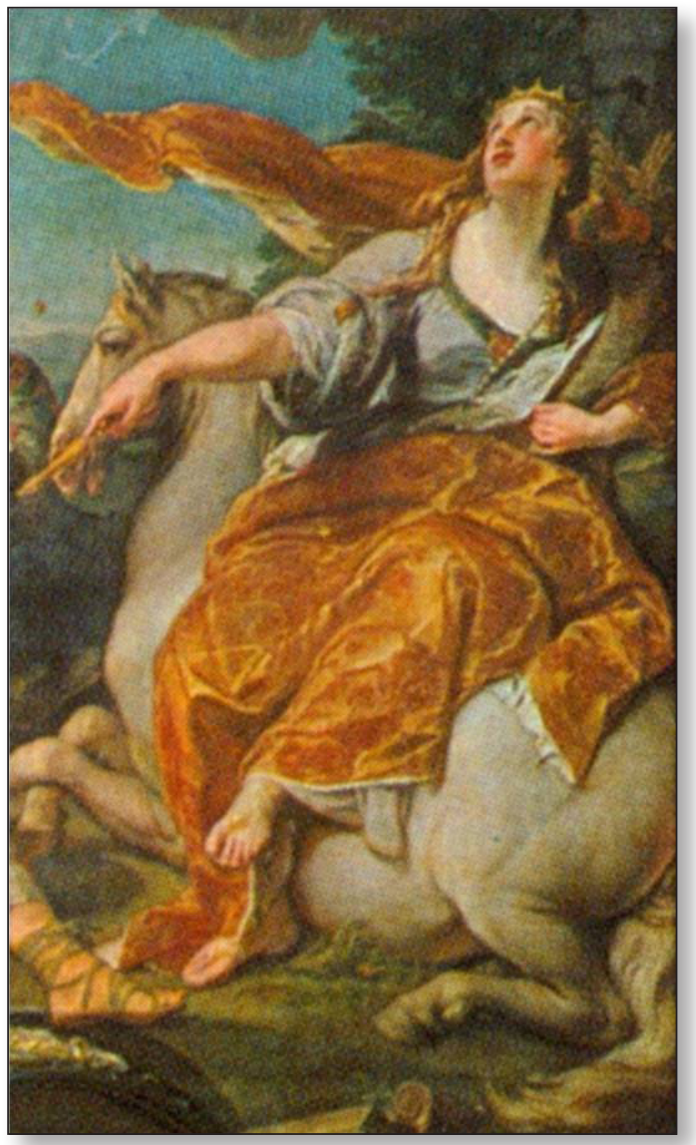

Fig. 5. Imagen simbólica de Europa (Detalle).

forma celebranda uenusta eminet; eoae gemmae per tempora perque colla micant, suaues thure incenduntur odores: deformis ceruice prope est gibboque camelus).

Tras esta descripción detallada de cada uno de los elementos que aparecen en el cuadro, el poeta (al igual que sucedió al inicio de la misma) hace un resumen de lo descrito, sin atreverse a destacar algo en concreto; todo es digno de alabanza: la viveza de los rostros, la sobriedad, las figuras con diferentes gestos, el decoro de los miembros, los fondos de sombras, los vestidos tejidos a medida, los miembros que se adivinan bajo los ropajes, la expresión en los rostros que son como palabras, la majestad [...]. Gracias a todas estas virtudes del 
pintor, la naturaleza confiesa ser vencida por el arte (Iam se natura libenter expressam penitus uictamue fatetur ab arte).

En los últimos veinticuatro versos (de similar extensión a la parte primera del poema), el poeta invita a la imagen del Sagrado Corazón a colocarse en el templo a ella dedicada, en donde recibirá plegarias, votos y culto permanente. Esto es lo que simboliza el ángel, que junto al Pontífice, sostiene un libro en el que se anuncia la elección de este lugar como eterna mansión del Corazón (puer alatus cera descriptus eadem Pontificem iuxta librum demonstrat [...]). Aquí vendrán a venerarle desde lugares lejanos, trayendo el oro brasileño y las maderas preciosas, el marfil angoleño y las perlas y piedras preciosas de Oriente. Igualmente, lo venerarán la Reina lusitana y su esposo, y su ejemplo seguirán otros pueblos de África y de Europa y de las dos Indias. Su fama se extenderá por todo lugar y tiempo.

La descriptio de Arévalo (canónica casi siempre, tanto en la simbología cristiana como en la pagana) no llega a ser exhaustiva; por ejemplo, nada dice del pelícano que está pintado en el frontal del altar, o del cuerno de la abundancia que sostiene Europa, o del carcaj, arco y flechas, así como del papagayo que están en la alusión a América. En otro orden de cosas, en la denominación que Arévalo da al animal que acaricia la mujer americana, dice tigrim manus altera mulcet [...]; hay que notar que tigris es la denominación común que desde la llegada de los españoles a América se dio a ese animal (en realidad, es un jaguar o tigre americano).

Termino esta aportación, trayendo a colación, por lo adecuado a estas reflexiones, el texto precisamente de un libro devocional, de muchísima influencia en el ámbito católico, titulado Schola cordis, de B. Haeften (1864, 11-12):

Hay entre esta [la poesía] y el arte de la pintura tal proporción, que lo que una explica con palabras, tropos y galanura de frases, la otra propone a la vista con diversidad de líneas, sombras y colores; y lo que las dos hallan más sublime en cualquier cosa, lo copian y acomodan al sujeto y al asunto que cada cual se propone, con tal viveza que parece no estudian ya en las personas y naturaleza, sino que a esta le dan leyes [...] Tienen estas, además del gusto que concilian, una secreta energía para mover los ánimos con suavidad y dulzura; siendo muy cierto lo que Horacio cantaba: Con más eficacia mueve lo que miran los ojos advertidos, que lo que solo suena en los oídos [...] El blanco a que he mirado en esta obra no ha sido otro que a deleitar, instruir y mover con estampas los ojos, con poemas los oídos, y con lecciones los ánimos.

\section{BIBLIOGRAFÍA}

Charbonneau-Lassay, L. [1983]. Estudios sobre simbología cristiana. Iconografía y simbolismo del Corazón de Jesús, Barcelona, José J. de Olañeta.

Díaz Patiño, G. [2010]. "Imagen y discurso de la representación religiosa del Sagrado Corazón de Jesús», PLURA, Revista de Estudos de Religiâo, l (1), 86-108.

Fernández Arrillaga, I. [1997]. «Profecías, coplas, creencias y devociones de los jesuitas expulsos durante su exilio en Italia», Revista de historia moderna, 16, 8398.

Gerbier, T.A.M. y SÁenz de Tejada, J.M. [1959]. Verdadera práctica de la devoción al Sagrado Corazón de Jesús, Barcelona, Luis Gili.

Haeften, B. [1864]. Escuela del Corazón, que escribió en lengua latina el R.P.D. Benito Haeften (1629), de la Orden de San Benito, y ha vertido en la Castellana Fr. Diego de Mecolaeta, de la misma orden, Barcelona, Imprenta del heredero de Pablo Riera.

Luengo, M. Colección de Papeles Varios, Archivo Histórico de Loyola, Estante 10. 


\section{César Chaparro Gómez}

Rey, E. [1958]. "Poema inédito de F. Arévalo, S. J., al Corazón de Jesús pintado por Batoni para la Basílica de la Estrella (1781) ", Humanidades, 19-20, 151-177.
Ruiz Sánchez, M. y Gallego Moya, E. [19971998]. "Dos himnos de F. Arévalo a la Virgen", Excerpta Philologica, 7-8, 271287. 